\title{
Endogenous Education and Long-Run Factor Shares
}

\author{
By Gene M. Grossman, Elhanan Helpman, Ezra Oberfield and Thomas Sampson*
}

\begin{abstract}
We study the determinants of factor shares in a neoclassical environment with capital-skill complementarity and endogenous education. In this environment estimates of the elasticity of substitution between capital and labor that fail to account for human capital levels will be biased upwards. We develop a model with overlapping generations, technology-driven neoclassical growth and ongoing increases in educational attainment. For a class of production functions featuring capital-skill complementarity, a balanced growth path exists and is characterized by an inverse relationship between the rates of capital- and labor-augmenting technological progress and the capital share in national income.

JEL: E25, J24, O41

Keywords: Neoclassical growth, Balanced growth, Human capital, Education, Technological progress, Capital-skill complementarity, Labor share, Capital share
\end{abstract}

Ever since John Maynard Keynes (1939, p.48) famously touted the stability of the capital and labor shares in national income as "one of the most surprising, yet best-established, facts in the whole range of economic statistics," growth theorists have been fascinated by the determinants of long-run factor shares and the reasons for their stability. Kaldor (1961) made the constancy of factor shares first of his six 'stylized' facts of economic growth and many economists have observed the continued stability of these shares well beyond the time of his writing. But, in recent years, the labor share declined precipitously, as has been documented and discussed by Elsby et al. (2013), Karabarbounis and Neiman (2014), and many others. Now, the factor shares may well have stabilized again, with workers receiving a new and smaller slice of the economic pie. ${ }^{1}$ These events have revived interest among growth economists in the determinants of the functional distribution of income.

If income shares are stable for long periods in the face of factor accumulation and (biased) technical progress, some equilibrating forces must be at work. A unitary aggregate elasticity of substitution between capital and labor could be one such force, because in a Cobb-Douglas world, any persistent divergence between the growth rates of the labor force and the capital stock would be offset by opposing trends in factor returns. But a large body of empirical research suggests that the elasticity of substitution is not equal to one. ${ }^{2}$ In Grossman et. al (2017a),

\footnotetext{
* Grossman: Princeton University, Department of Economics, Princeton, NJ 08544 (e-mail: grossman@princeton.edu); Helpman: Harvard University and CIFAR, 1805 Cambridge Street, Cambridge, MA 02138 (e-mail: ehelpman@harvard.edu); Oberfield: Princeton University, Department of Economics, Princeton, NJ 08544 (e-mail: edo@princeton.edu); Sampson: London School of Economics, Centre for Economic Performance, Houghton Street, London, WC2A 2AE, United Kingdom (e-mail: t.a.sampson@lse.ac.uk). This paper evolved from our earlier working paper, "The Productivity Slowdown and the Declining Labor Share: A Neoclassical Exploration," although the focus of the paper has changed substantially. We are grateful to Ben Bridgman, Andrew Glover, Chad Jones, Jacob Short, Gianluca Violante, and Ariel Weinberger for discussions and suggestions on the earlier paper.

${ }^{1}$ See, for example, U.S. Bureau of Labor Statistics, Nonfarm Business Sector: Labor Share [PRS85006173], retrieved from FRED, Federal Reserve Bank of St. Louis; https://fred.stlouisfed.org/series/PRS85006173, March 8, 2020.

${ }^{2}$ See, for example, Chirinko (2008, p.671), who surveyed many studies that sought to measure this elasticity and concluded that "the weight of the evidence usggests a value of [the elasticity of substitution] in the range of 0.4 to 0.6." In research conducted after that survey was written, Karabarbounis and Neimann (2014) estimate an elasticity of substitution
} 
we suggested another possible equilibrating force: the endogenous response of education to a rise in the return to schooling could stabilize factor shares in the face of ongoing declines in the prices of investment goods if the aggregate technology exhibits complementarity between capital and skills. ${ }^{3}$

Our previous paper focused on the requirements for balanced growth. We explored a model with fleeting lifespans and derived necessary and sufficient conditions for constant steady-state factor shares in the presence of ongoing capital-augmenting technological progress and a nonunitary aggregate elasticity of substitution between capital and labor. In particular, we identified a class of aggregate production functions characterized by capital-skill complementarity that deliver balanced growth. However, our model could not speak to changes in the steadystate factor shares, because our convenient assumption of fleeting lives severed all links between these shares and parameters of the growth process.

In this paper, we allow for longer lives, which renders investment in education a forwardlooking decision. In the body of our text, we focus on a model in which all individuals accumulate human capital by spending time in school. But our results are not limited to this model of educational attainment; in the appendix, we establish similar results in a model of discrete occupational choice with endogenous fractions of the population opting to become skilled.

We begin in Section I by examining the link between equilibrium factor shares, levels of human capital, and the rental rate for capital in a competitive economy with an aggregate production function characterized by capital-skill complementarity. In such a setting, a greater level of human capital goes hand in hand with a greater capital share, whereas an inverse relationship exists between the rental rate and the capital share whenever the elasticity of substitution between capital and raw labor falls short of one. In Section II, we introduce schooling as an intertemporal choice for overlapping generations of the population. In our setting of "perpetual youth" with a constant hazard rate of death, it is optimal for members of each generation to attend school fully until they achieve a (time-varying) target level of human capital, whereupon they enter the work force but continue their education part-time to keep pace with the growing human-capital threshold. When capital and skills are complementary, there is an inverse equilibrium relationship between the education target and both the rental rate on capital and the difference between the interest rate and the growth rate of wages. Taken together, the results in Sections I and II imply that failing to control for variation in human capital will lead to upward bias in estimates of the elasticity of substitution between capital and labor in an economy with capital-skill complementarity.

Finally, in Section III, we close the model and study neoclassical growth driven by exogenous technological progress. The dynamic equilibrium features ongoing accumulation of physical and human capital. We establish the existence of a unique balanced growth path when skills are complementary to capital and human capital enters the aggregate production function in a particular way. Along this path, the downward pressure on the capital share due to accumulation of better and cheaper machinery is offset by upward pressure from investments in skills that are complementary to those machines. In the long run, the human capital target

substantially greater than one, while Herrendorff et. al (2015) find an elasticity of 0.84 and Oberfield and Raval (2020) estimate it between 0.5 and 0.7 for the U.S. manufacturing sector.

${ }^{3}$ Acemoglu (2003) proposes yet another equilibrating force: when firms choose between capital-augmenting and laboraugmenting technological improvements, they may tend toward only the latter in the long run. In his setting, factor shares evolve during a transition phase with capital-augmenting progress, but stabilize in the steady state due to the eventual dominance of technical change directed to labor. One difficulty with this story is that quality-adjusted prices of capital goods have declined signficantly over long periods, suggesting an ongoing process of investment-specific technological change. 
conditional on technology levels is decreasing in the difference between the real interest rate (which makes workers more impatient) and the growth rate of wages conditional on human capital (which makes human capital more valuable). A slowdown in productivity growth-be it capital augmenting or labor augmenting - reduces the interest rate by more than wage growth whenever the intertemporal elasticity of substitution is below one. Consequently, slower growth induces human capital accumulation that leads to a higher capital share and a lower labor share.

\section{Human Capital and Factor Shares}

In this section, we examine the relationship between human capital and the functional distribution of income in a general, neoclassical production environment. To this end, we write $Y=F(K, L ; h)$, where $Y$ is aggregate output, $K$ and $L$ are physical inputs of capital and labor, and $h$ is some measure of the human capital embodied in that labor. This formulation admits various interpretations for $h$. For example, $h$ might measure the education achieved by the representative worker, as in Grossman et al. (2017a). Or, $h$ might represent the fraction of the labor force that is "skilled", with the remaining fraction being "unskilled". Then, we could write a three-factor production function $G(K, S, U)$ as in Krusell et al. (2000), with $S$ and $U$ denoting inputs of skilled and unskilled labor, respectively, so that $F(K, L ; h) \equiv G(K, h L,(1-h) L)$.

We focus on technologies that exhibit constant returns in the physical inputs, $K$ and $L$, and that feature capital-skill complementarity. We define capital-skill complementarity in terms of the effect of capital accumulation on the marginal product of human capital relative to that of raw labor and invoke

ASSUMPTION 1: $F(K, L ; h)$ is homogeneous of degree one in $K$ and $L$ and exhibits capitalskill complementarity; i.e., $\varphi \equiv d \log \left(F_{h} / F_{L}\right) / d \log K>0$ for all $h, L$, and $K$.

In the most common treatment of human capital, output is taken to be a function of aggregate capital and "efficiency labor," where the latter is defined as the product of raw labor and a productivity term reflecting average human capital per worker; see, for example, Uzawa (1965) and Lucas (1988). In that specification, raw labor and skill are perfect substitutes and thus capital accumulation impacts their returns similarly. But, following Griliches (1969), Krusell et al. (2000) have emphasized the empirical relevance of capital-skill complementarity and the role it has played in determining the evolution of factor rewards. Using their threefactor production function, $G(K, S, U)$, they associated capital-skill complementarity with a technology in which capital substitutes more closely for unskilled labor than for skilled labor. Our definition coincides with theirs when $G(\cdot)$ takes a nested-CES form (as they assume), ${ }^{4}$ while extending the definition to a broader range of production technologies and interpretations of human capital. ${ }^{5}$

Now suppose that the economy is competitive and capital is hired up to the point where its marginal product is equal to the rental rate $R$, or $F_{K}(K, L ; h)=R$. Define $\theta \equiv R K / Y$ as the capital share in national income (so that $1-\theta$ is the labor share) and $\sigma \equiv\left(F_{K} F_{L}\right) /\left(F F_{K L}\right)$ as the elasticity of substitution between capital and labor for a fixed level of human capital, $h$. Then, using the definitions of $\varphi, \sigma$, and $\theta$ and the first-order condition, $F_{K}(K, L ; h)=R$, it is

\footnotetext{
${ }^{4}$ See the appendix for proof of this claim.

${ }^{5}$ With constant returns to scale, we can allow $F(\cdot)$ to represent the output of a "production unit" that employs $K$ units of capital and $L$ units of labor with human capital $h$. Then, aggregate output is the sum of outputs across all production units. In this manner, we can accomodate non-degenerate distributions of human capital across workers in the labor force.
} 
straightforward to show that ${ }^{6}$

$$
d \theta=(1-\sigma) \theta d \ln R+\sigma \varphi \frac{F_{h}}{F} d h .
$$

Equation (1) relates changes in the capital share to changes in the rental rate and changes in the measure of human capital. In the absence of capital-skill complementarity (i.e., if $\varphi=0$ ) the second term drops out and the capital share rises when the rental rate falls if and only if $\sigma>1$. The positive relationship between changes in the labor share and changes in the rental rate (proxied by changes in the relative price of investment) in cross-country data provides the basis for Karabarbounis and Neiman's (2014) estimation of an elasticity of substitution between capital and labor in excess of one and their attribution of approximately half of the fall in the global labor share in recent years to the fall in the relative price of investment goods since 1975. However, in addition to the usual concerns about the possible endogeneity of $R$, there is the additional issue that their estimation fails to control for growth in educational attainment, which was widespread in their sample. According to (1), a failure to control for $d h$ will generate an upward bias in estimates of $\sigma$ in the presence of capital-skill complementarity whenever $R$ and $h$ are negatively correlated. As we shall see, such a negative correlation is a natural outcome in models of optimal human capital accumulation.

\section{Determinants of Optimal Education}

In Grossman et al. (2017a) we developed a model of growth with endogenous education and capital-skill complementarity. We were interested there in the necessary and sufficient conditions for balanced growth, so we invoked a useful shortcut: we assumed that successive generations of workers survive only for an instant, during which they divide their fleeting time between work and education to maximize instantaneous income. This shortcut was helpful, because it circumvented thorny aggregation issues; we know of no overlapping generations models in which educational attainment grows in a steady state. Unfortunately, by removing intertemporal considerations from the schooling problem, we severed all links between factor shares and the growth process, because without forward-looking investment, the parameters of the static production function fully determine the functional distribution of income.

To study the determinants of long-run factor shares, we require a setting with meaningful, intertemporal tradeoffs. To this end, we wed a model of overlapping generations à la Yaari (1965) and Blanchard (1985) with a model of human capital investment à la Ben Porath (1967). Cohorts born at every instant exist in a state of "perpetual youth." New generations are born continuously. While alive, individuals divide their time between schooling and work. The cumulation of these choices determines each individual's human capital and thus the supply of skills in the aggregate. ${ }^{7}$

Our economy is populated by a unit mass of identical family dynasties. ${ }^{8}$ The representative dynasty comprises a continuum of individuals of mass $N_{t}$ at time $t$. Each living individual generates a new member of her dynasty with a constant, instantaneous probability $\lambda d t$ in a period of length $d t$ and faces a constant instantaneous risk of demise $\nu d t$ in that same period,

\footnotetext{
${ }^{6}$ See the appendix.

${ }^{7}$ The main text focuses soley on educational attainment. But in the appendix we show that we can achieve similar results in a model of occupational choice.

${ }^{8}$ We assume that families maximize dynastic utility, including the discounted well-being of unborn generations. Similar qualitative results would be attained in a Yaari (1965) economy with (negative) life insurance and no bequests, as developed in Blanchard and Fischer (1989, ch.3).
} 
with $\lambda>0, \nu \geq 0$. With these constant hazard rates of birth and death, the size of a dynasty at time $t$ is given by

$$
N_{t}=e^{(\lambda-\nu)\left(t-t_{0}\right)} N_{t_{0}}
$$

Each newborn enters the world devoid of human capital. An individual is endowed at each instant with a unit of time that she can divide arbitrarily between working and learning. Work yields a wage at time $t$ that reflects the extant technology and the size of the aggregate capital stock, as well as the individual's accumulated human capital, $h_{t}$. Learning occurs at full-time school or in continuing education. An individual who devotes a fraction $\ell_{t}$ of her time to work and the remaining fraction $1-\ell_{t}$ to education accumulates human capital according to

$$
\dot{h}_{t}=1-\ell_{t}
$$

The time constraint implies $\ell_{t} \in[0,1] .^{9}$

The representative family maximizes dynastic utility,

$$
U_{t_{0}}=\int_{t_{0}}^{\infty} e^{-\rho\left(t-t_{0}\right)} N_{t} \frac{c_{t}^{1-\eta}-1}{1-\eta} d t
$$

subject to an intertemporal budget constraint, where $c_{t}$ is per capita consumption by family members at time $t, \eta$ is the inverse of the elasticity of intertemporal substitution, and $\rho$ is the subjective discount rate. As usual, the Euler equation implies

$$
\frac{\dot{c}_{t}}{c_{t}}=\frac{r_{t}-\rho}{\eta}
$$

where $r_{t}$ is the real interest rate in terms of consumption goods at time $t$. To limit the number of cases and to conform with widespread empirical evidence, we assume that $\eta>1 .{ }^{10}$

Considering that there is a continuum of members in every dynasty and that families maximize dynastic utility, each individual chooses the path of her time allocation $\left\{\ell_{t}\right\}$ to maximize the expected present value of earnings. For an individual born at time $\tau$, the problem is

$$
\max \int_{\tau}^{\infty} e^{-\int_{\tau}^{t}\left(r_{z}+\nu\right) d z} \ell_{t} w_{t}\left(h_{t}\right) d t
$$

subject to $h_{\tau}=0, \dot{h}_{t}=1-\ell_{t}$, and $0 \leq \ell_{t} \leq 1$, where $w_{t}\left(h_{t}\right)$ is the wage schedule that relates compensation at time $t$ to the worker's human capital. Let $\mu_{t}$ be the costate variable associated with human-capital accumulation. Then the first-order conditions imply

${ }^{9}$ In this formulation, current human capital plays no role in the learning process. However, we could as easily specify

$$
\dot{H}_{t}=H_{t}^{\varsigma}\left(1-\ell_{t}\right), \varsigma \in[0,1],
$$

with $H_{0}=1$. This would generate an alternative measure of human capital that is just a monotonic transformation of $h_{t}$ and that would play the same role as $h_{t}$ in the analysis that follows. For example, if $\varsigma=1$,

$$
\log H_{t}=\int_{0}^{t}\left(1-\ell_{z}\right) d z=h_{t}
$$

where the second equality follows from the assumption that $h_{0}=0$.

${ }^{10}$ See, for example, Hall (1988), Campbell (2003) and Yogo (2004) for estimates using macro data, and Attanasio and Weber (1993) and Vissing and Jorgenson (2002) for estimates using micro data. 


$$
\left.\begin{array}{c}
w_{t}\left(h_{t}\right)<\mu_{t} \\
w_{t}\left(h_{t}\right)=\mu_{t} \\
w_{t}\left(h_{t}\right)>\mu_{t}
\end{array}\right\} \Rightarrow\left\{\begin{array}{c}
\ell_{t}=0 \\
\ell_{t} \in[0,1] \\
\ell_{t}=1
\end{array}\right.
$$

and

$$
\dot{\mu}_{t}=\left(r_{t}+\nu\right) \mu_{t}-\ell_{t} w_{t}^{\prime}\left(h_{t}\right)
$$

In this setting, the optimal schooling problem typically has a simple, bang-bang solution. ${ }^{11}$ Members of each cohort attend school full-time beginning at birth, until they accumulate human capital equal to a time-varying threshold, $h_{t}^{*}$. Then, the "graduates" enter the labor force, but they continue on with their education to maintain their human capital equal to the (growing) threshold. This education strategy implies that all workers in the labor force share a common level of human capital $h_{t}=h_{t}^{*}$, irrespective of their birth dates.

The human capital threshold $h_{t}^{*}$ equals the education level at which an individual is indifferent between school and work. The benefit of additional schooling is the present value of human capital, $\mu_{t}$, while the instantaneous cost is the foregone wage, $w_{t}$. Substituting $\mu_{t}=w_{t}\left(h_{t}^{*}\right)$ in (5) and rearranging terms gives

$$
r_{t}+\nu-g_{w \mid h_{t}^{*}, t}=\frac{w_{t}^{\prime}\left(h_{t}^{*}\right)}{w_{t}\left(h_{t}^{*}\right)}
$$

where $g_{w \mid h, t}$ is the growth rate of wages (for a given level of human capital, $h$ ) at time $t$. Then, as we show formally in the appendix, for any aggregate production function $F(\cdot)$ that satisfies Assumption 1 and that generates an interior choice of $h_{t}^{*}$, (6) gives an inverse relationship between human capital and both the rental rate on capital and the difference between the interest rate and the growth rate of wages. The former observation underlies our claim at the end of Section 2 that optimal human capital accumulation implies a negative correlation between $h$ and $R$ when capital and skill are complementary. Intuitively, when a rise in the rental rate reduces demand for capital, it also reduces the marginal returns to skill, $w_{t}^{\prime}\left(h_{t}^{*}\right) / w_{t}\left(h_{t}^{*}\right)$. So, the demand for education also falls. Meanwhile, the latter observation-which does not require capital-skill complementarity - shows that the growth process also influences human capital accumulation inasmuch as a high interest rate discourages investment while a high rate of wage growth makes additional schooling more attractive.

\section{Optimal Education and Balanced Growth}

To study the determinants of long-run factor shares, we need to close the model. We prefer to do so in a way that preserves balanced growth, both for reasons of tractability and because factor shares were stable for decades after WWII and, after a substantial realignment over some twenty years, seem to have stabilized again.

The task of generating a balanced growth path might seem daunting. First, the presence of ongoing capital-augmenting technical progress is inconsistent with constant factor shares in a standard neoclassical setting with a non-unitary elasticity of substitution between capital

\footnotetext{
A1.

${ }^{11}$ In the appendix, we show that the bang-bang solution is optimal under the technical conditions detailed in Assumption
} 
and labor; see Uzawa (1961). Yet, Gordon (1990), Greenwood et. al (1997) and others have documented a significant decline in the relative price of capital, which is suggestive of capitalaugmenting progress. Second, a falling rate of return on capital goes hand in hand with ongoing human-capital accumulation, which means that different cohorts will target different levels of education before entering the labor force. Aggregation becomes an immediate technical concern. Third, growing educational attainment means falling labor force participation and so the growth rate of labor supply need not be constant. Yet, capital accumulates at a constant rate along a balanced growth path (BGP). Despite these hurdles, we are able to close our model in a way that admits balanced growth by building upon the insights in Grossman et.al (2017a). By combining the technology introduced in that paper with the Yaari-Blanchard model of overlapping-generations and the Ben Porath (1967) model of educational investment, we are able to solve for a BGP and to study its properties.

To generate long-run growth, we introduce capital and labor-augmenting technology into the model of Section I. A firm that hires $K$ units of capital and $L$ units of labor with human capital $h$ produces

$$
Y_{t}=F\left(A_{t} K, B_{t} L, h\right)
$$

units of output at time $t$, where $A_{t}$ now represents the state of disembodied, capital-augmenting technology and $B_{t}$ the state of labor-augmenting technology. ${ }^{12}$ We retain Assumption 1 from Section I, which imposes capital-skill complementarity and constant returns to scale; the latter allows us to use (7) also for the aggregate production function. Next we borrow from Grossman et al. (2017a) the assumption that $F(\cdot)$ falls within a particular class of production functions, namely:

ASSUMPTION 2: The production function can be written as $F\left(A_{t} K, B_{t} L, h\right)=\tilde{F}\left(e^{-a h} A_{t} K, e^{b h} B_{t} L\right)$, with $a>0, b>\lambda \geq 0$, where

(i) $f(k) \equiv \tilde{F}(k, 1)$ is strictly increasing, twice differentiable, and strictly concave for all $k$;

(ii) $\lim _{k \rightarrow 0} k f^{\prime}(k) / f(k)<b /(a+b)$.

As we discussed in our earlier paper, this class of production functions makes schooling akin to capital-using (or labor-saving) technical progress; i.e., an increase in human capital raises the demand for capital relative to that for raw labor at the initial factor prices. While it may be tempting to interpret Assumption 2 as positing that human capital reduces the efficiency of physical capital, the fact that $h$ enters $\tilde{F}(\cdot)$ in two places renders this interpretation specious. To see this, note that Assumption 2 is formally equivalent to assuming that the production function can be written as

$$
F\left(A_{t} K, B_{t} L, h\right)=\left(B_{t} L\right)^{1-\beta} \mathcal{F}\left(A_{t} K, e^{b h / \beta} B_{t} L\right)^{\beta},
$$

with $\beta=b /(a+b)$. This alternative formulation expresses output as a Cobb-Douglas function of raw labor and a composite input produced by capital and a measure of worker skills. Then it is clear that $h$ raises the marginal productivity of physical capital for any $K$; i.e., human

\footnotetext{
${ }^{12}$ Recall from Section II that all workers in the labor force have the same human capital, so we do not need to specify the output by heterogeneous labor. If workers were to differ in skills, we could subdivide each firm into units with homogeneous labor and sum the output across these units; see footnote 5.
} 
capital accumulation shifts the $K-L$ isoquants inward while at the same time rotating them to induce greater demand for capital. Together with Assumption 1 that stipulates capital-skill complementarity, our restriction on the technology ensures $\sigma<1$, which is in keeping with the findings of Oberfield and Raval (2020), who estimate $\sigma$ from a factor-share equation after controlling for workers' human capital. Assumption 2.ii ensures that the marginal product of human capital is positive for all $K, L$, and $h$.

Output can be used for consumption or investment. A unit of output produces one unit of the consumption good or $q_{t}$ units of the investment good at time $t$, where growth in $q_{t}$ captures investment-specific technological change, as in Greenwood et al. (1997). Thus,

$$
Y_{t}=C_{t}+I_{t} / q_{t}
$$

and

$$
\dot{K}_{t}=I_{t}-\delta K_{t}
$$

where $C_{t}$ and $K_{t}$ are aggregate consumption and the aggregate capital stock, respectively, $I_{t}$ is gross investment, and $\delta$ is the constant rate of capital depreciation.

Technology evolves exogenously in our model. Let $\gamma_{L}=\dot{B} / B$ be the constant rate of labor-augmenting technological progress, $g_{A}=\dot{A} / A$ the constant rate of disembodied capitalaugmenting progress, and $g_{q}=\dot{q} / q$ the constant rate of embodied (or investment-specific) technological progress. Define $\gamma_{K} \equiv g_{A}+g_{q}$ as the total rate of capital-augmenting technological progress. We are interested in the relationship between these parameters that describe the growth process and the long-run factor shares.

\section{A. Characterizing a Balanced Growth Path}

In order to solve for a BGP, we impose some further parameter restrictions.

ASSUMPTION 3: The parameters of the economy satisfy

(i) $a>\gamma_{K}$;

(ii) $\lim _{k \rightarrow 0} \frac{k f^{\prime}(k)}{f(k)}>\frac{\Omega}{1+\Omega}>\lim _{k \rightarrow \infty} \frac{k f^{\prime}(k)}{f(k)}$, where $\Omega \equiv \frac{b-\lambda}{a}-\frac{(\eta-1)\left(\gamma_{L}+\frac{b-\lambda}{a} \gamma_{K}\right)+\rho-(\lambda-\nu)}{a-\gamma_{K}}$;

(iii) $(\eta-1)\left(\gamma_{L}+\frac{b-\lambda}{a} \gamma_{K}\right)+\rho-(\lambda-\nu)>0$.

Assumption 3 ensures the existence of an equilibrium with finite dynastic utility. It also generates interior choices for continuing education among those that have already joined the labor force.

A competitive firm takes the rental rate as given. A firm that hires a unit of labor bearing human capital $h$ at time $t$ will combine that labor with $\kappa_{t}(h)$ units of physical capital, where $\kappa_{t}(h)$ is given implicitly by

$$
e^{-a h} A_{t} \tilde{F}_{K}\left[e^{-a h} A_{t} \kappa_{t}(h), e^{b h} B_{t}\right]=R_{t} .
$$

The worker is paid her marginal product, which, with constant returns, is the difference between revenue and capital costs, or

$$
w_{t}(h)=\tilde{F}(\cdot)-e^{-a h} A_{t} \kappa_{t}(h) \tilde{F}_{K}(\cdot) .
$$


Individuals use the wage schedule $w_{t}(h)$, together with their rational expectations of the evolution of wages and the interest rate to make their optimal schooling decisions, summarized in (6).

Let us define a BGP as a dynamic equilibrium with constant growth rates of output, consumption, and capital, and with factor income shares that are constant and strictly positive. A constant growth rate of consumption implies a constant interest rate, by the Euler equation (3). We conjecture a constant division of time between work and education, $\ell$, for those that have completed full-time school. We prove in the appendix the following lemma that describes important features of the BGP:

LEMMA 1: Suppose $g_{q}, g_{A}$ and $\gamma_{L}$ are constants and Assumptions1, 2 and 3 are satisfied. Then there exists a unique BGP characterized by

$$
\ell=1-\frac{\gamma_{K}}{a}
$$

and

$$
z_{t} \equiv \frac{e^{-a h_{t}^{*}} A_{t} K_{t}}{e^{b h_{t}^{*}} B_{t} L_{t}}=z^{*} \text { for all } t
$$

Here, $z_{t}$ adjusts the effective capital-labor ratio at time $t$ (i.e., $A_{t} K_{t} / B_{t} L_{t}$ ) for the prevailing level of human capital of those in the workforce, taking into account the different complementarity between human capital and each of the primary factors of production. We henceforth refer to $z_{t}$ as the schooling-adjusted effective capital-to-labor ratio.

Equation (10) implies that the human capital threshold increases linearly with time,

$$
\dot{h}_{t}^{*}=\frac{\gamma_{K}}{a} .
$$

The optimal schooling strategies are depicted in Figure 1. Here, the lines with unit slope represent the human capital accumulation by each cohort whilst its members remain full-time students. Once a cohort's human capital reaches $h_{t}^{*}$, the members devote a fraction $\gamma_{K} / a$ of their time to continuing education, just like all others that have completed their full-time schooling.

Let $s_{\tau}$ denote years in full-time school (or "educational attainment") for the cohort born at time $\tau$. This is the time it takes for them to catch up with the human capital threshold, i.e., $s_{\tau}=h_{\tau+s_{\tau}}^{*}$. With the threshold rising according to (12), $h_{\tau+s_{\tau}}^{*}=h_{\tau}^{*}+s_{\tau} \gamma_{K} / a$. Thus, educational attainment also increases linearly,

$$
\dot{s}_{\tau}=\frac{\gamma_{K}}{a-\gamma_{K}} .
$$

Recalling that $a>\gamma_{K}$ by Assumption 3.i, educational attainment rises in the steady state if and only if the rate of capital-augmenting technical progress is strictly positive.

Lemma 1 states that the schooling-adjusted effective capital-labor ratio converges to a constant value, $z^{*}$, in the long run. ${ }^{13}$ This is the key to balanced growth in the presence of

\footnotetext{
${ }^{13}$ In our working paper with a different title and focus, Grossman et al. (2017b), we used numerical methods to suggest the presumed stability of the BGP.
} 


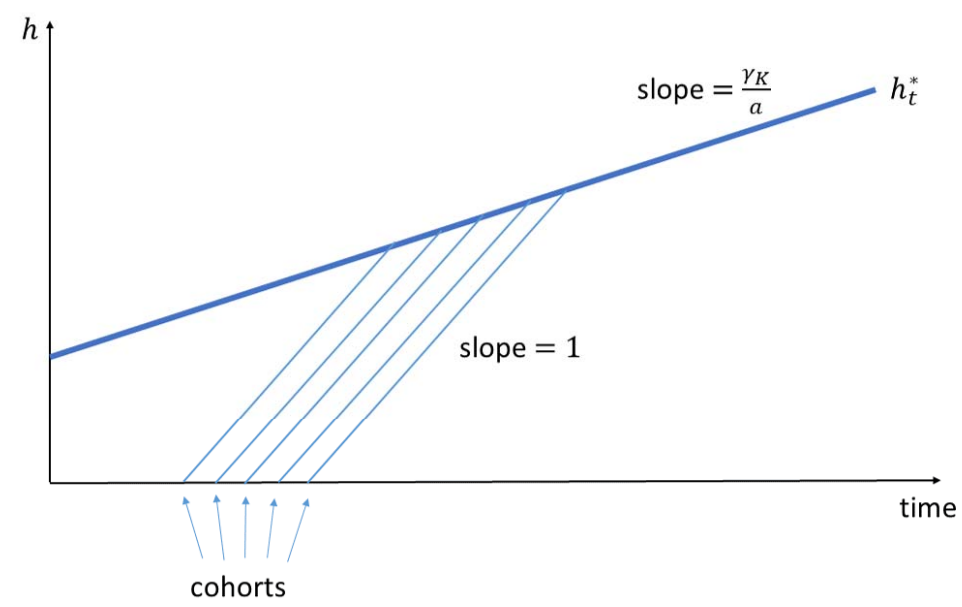

Figure 1. Human Capital Accumulation by Birth Cohort

capital-augmenting technological progress and an elasticity of substitution between capital and labor less than one. As capital accumulates and becomes more productive, the capital share in national income would tend to fall when $\sigma<1$. However, the capital-skill complementarity implies an increased return to schooling. The extra schooling is capital-using, which puts upward pressure on the capital share. For the class of production functions described in Assumption 2, the offsetting forces just balance, and the capital share remains constant. ${ }^{14}$

Why then is it optimal for active workers to upgrade their human capital continuously so as to keep $z_{t}$ constant? For an interior choice of $\ell \in(0,1)$, the indifference condition (6) must be satisfied in the steady state, when $r_{t}$ and $g_{w \mid h_{t}^{*}, t}$ are constants. Meanwhile, Assumption 2 implies

$$
\frac{w_{t}^{\prime}\left(h_{t}\right)}{w_{t}\left(h_{t}\right)}=b-a \frac{\theta\left[z_{t}\left(h_{t}\right)\right]}{1-\theta\left[z_{t}\left(h_{t}\right)\right]}
$$

where $\theta\left(z_{t}\right) \equiv z_{t} f^{\prime}\left(z_{t}\right) / f\left(z_{t}\right)$ is the capital share. Notice that the capital share depends only on the schooling-adjusted effective capital-to-labor ratio. So, a choice of $h_{t}^{*}$ that keeps $z_{t}$ constant also keeps $w_{t}^{\prime}\left(h_{t}^{*}\right) / w_{t}\left(h_{t}^{*}\right)$ constant, which is consistent with the steady-state requirements of $(6) .{ }^{15}$

Using the optimal allocation of time, we can now calculate the (constant) growth rates of the labor force, wages, and output per capita, along with the constant interest rate and capital share. The aggregate labor force at time $t$ is the product of the fraction of time that the typical worker devotes to gainful employment and the mass of the surviving population that has completed its phase of full-time schooling. The measure of individuals that were born at $\tau$ and that are still alive at $t$ is $\lambda N_{\tau} e^{-\nu(t-\tau)}=\lambda N_{t} e^{-(\lambda-\nu)(t-\tau)} e^{-\nu(t-\tau)}=\lambda N_{t} e^{-\lambda(t-\tau)}$. All those

\footnotetext{
${ }^{14}$ Put differently, (12) implies that $e^{-a h_{t}^{*}} A_{t} q_{t}$ is constant along a BGP. So, the induced investment in human capital is just what is needed to offset the exogenous improvement in capital productivity.

15 Note that for (14) to be satisfied with a constant value of $z_{t}$, we need a sufficiently large range for $z f^{\prime}(z) / f(z)$. We show in the appendix that Assumption 3.ii guarantees the existence of a solution to (14).
} 
who were born at or before $t-h_{t}^{*}$ have already entered the labor force. Therefore,

$$
\begin{aligned}
L_{t} & =\left(1-\frac{\gamma_{K}}{a}\right) \int_{-\infty}^{t-h_{t}^{*}} \lambda N_{t} e^{-\lambda(t-\tau)} d \tau \\
& =\left(1-\frac{\gamma_{K}}{a}\right) N_{t} e^{-\lambda h_{t}^{*}}
\end{aligned}
$$

It follows from (15) that labor-force participation, $L_{t} / N_{t}$, shrinks at the rate $g_{L}-g_{N}=$ $-\lambda \gamma_{K} / a<0$. Declining labor-force participation mirrors increasing educational attainment, which requires longer stays in school for successive cohorts.

Next we derive the growth rate of wages. Compensation rises thanks to ongoing technological progress, as well as ongoing investments in physical and human capital. Using (8) and (9), we calculate that, along a BGP, the wage paid to each worker in the labor force (who has growing human capital of $h_{t}^{*}$ ) increases at rate $^{16}$

$$
g_{w}=\gamma_{L}+\frac{b}{a} \gamma_{K}
$$

Since factor shares are constant along the BGP, aggregate output is proportional to labor income, so the growth rate of output per capita can be expressed as

$$
\begin{aligned}
g_{y} & =g_{w}+g_{L}-g_{N} \\
& =\gamma_{L}+\frac{b-\lambda}{a} \gamma_{K} .
\end{aligned}
$$

Combining this expression with Assumption 3.iii implies that the present value of utility is finite. Also, per capita consumption is proportional to per capita output, so (3) gives the long-run interest rate,

$$
\begin{aligned}
r & =\rho+\eta g_{y} \\
& =\rho+\eta\left(\gamma_{L}+\frac{b-\lambda}{a} \gamma_{K}\right)
\end{aligned}
$$

Finally, we come to the steady-state factor shares. In the steady state, (6) and (14) imply

$$
\gamma_{L}+\frac{b}{a} \gamma_{K}=r+\nu-\left(1-\frac{\gamma_{K}}{a}\right)\left(b-a \frac{\theta}{1-\theta}\right)
$$

\footnotetext{
${ }^{16}$ We substitute for the arguments of $\tilde{F}(\cdot)$ and $\tilde{F}_{K}(\cdot)$ using $z=e^{-(a+b) h_{t}^{*}} A_{t} \kappa_{t}\left(h_{t}^{*}\right) / B_{t}$ and note that $z$ is constant along a BGP. The no-arbitrage condition for capital accumulation implies that $R_{t} q_{t}-\dot{q}_{t} / q_{t}-\delta=\iota_{t}$, and thus, when the interest rate and the rate of investment-specific technical progress are constant, $R_{t} / R_{t}=-g_{q}$. Totally differentiating (8) and (9) with $z$ constant implies

and$$
-g_{q}=g_{A}-a \dot{h}_{t}^{*}
$$$$
\frac{\dot{w}_{t}}{w_{t}}=\gamma_{L}+b \dot{h}_{t}^{*},
$$

from which it follows that

$$
\frac{\dot{w}_{t}}{w_{t}}=\gamma_{L}+\frac{b}{a} \gamma_{K}
$$
}


or

$$
\frac{\theta}{1-\theta}=\frac{b+\gamma_{L}-(r+\nu)}{a-\gamma_{K}}
$$

Next we substitute for the long-run interest rate, using (16), which gives us a relationship between the long-run capital share and the primitive parameters of the economy, namely

$$
\frac{\theta}{1-\theta}=\frac{b-\lambda}{a}-\frac{(\eta-1)\left(\gamma_{L}+\frac{b-\lambda}{a} \gamma_{K}\right)-\lambda+\nu+\rho}{a-\gamma_{K}} .
$$

We summarize our characterization of the BGP as follows:

PROPOSITION 1: Suppose the aggregate production function obeys Assumptions 1 and 2, the parameters satisfy Assumption 3 and $g_{q}, g_{A}$ and $\gamma_{L}$ are constant. Then there exists a unique balanced growth path along which new cohorts are full-time students until their human capital reaches a threshold $h_{t}^{*}$ that grows linearly with time. Once a cohort enters the labor force, its members devote a constant fraction $\ell=1-\gamma_{K} /$ a of their time to work and the remainder to continuing education. Wages grow at constant rate $\gamma_{L}+(b / a) \gamma_{K}$ and per capita income grows at constant rate $\gamma_{L}+(b-\lambda) \gamma_{K} / a$. The long-run real interest rate is given by (16) and the long-run factor shares are given by (18).

\section{B. Determinants of Long-Run Factor Shares}

We are ready to discuss the determinants of the long-run distribution of national income. We begin with (17), which expresses $\theta$ as a function of $\gamma_{K}$ and $\gamma_{L}$, taking the real interest rate as given. If, for example, the aggregate economy comprises a continuum of small regional economies or similar industries that face a common interest rate due to nationwide asset trade, then (17) would describe the cross-sectional relationship between growth rates of output and factor shares. From this equation, it is clear that $\theta$ would be positively correlated with both $\gamma_{K}$ and $\gamma_{L}$ in the cross section; regions and industries with faster rates of capital or laboraugmenting technological progress would have higher shares of their income paid to capital in an economy with a uniform interest rate.

But in a closed economy (or a global economy), the interest rate is endogenous and responds to changes in the growth process. Equation (18) informs us about the long-run relationship between factor shares and rates of technological progress. Recall our assumption that $\eta>1$, i.e., that the elasticity of intertemporal substitution is less than one. By differentiating the expression on the-right hand side of (18) and making use of Assumption 2.iii, we establish our key result:

PROPOSITION 2: When $\eta>1$, an increase in $\gamma_{K}$ or $\gamma_{L}$ raises the long-run labor share, $1-\theta$.

Proposition 2 states than an acceleration of technological progress of any sort will shift the distribution of national income from capital to labor. Of course, a productivity slowdown does just the opposite. Our model thus predicts a negative correlation between the growth rate and the capital share across steady states.

What accounts for this shift in factor shares? Note first from (16) that, in response to an exogenous shock to the growth process, the interest rate moves in the same direction as the growth rate of per capita income. Moreover, with $\eta>1$, the response of the former is 
greater than that of the latter. Thus, an acceleration of technological progress that causes $g_{y}$ to rise will cause $r-g_{y}$ to rise as well. On a BGP, wages grow at rate similar to per capita income, so $r-g_{w \mid h}$ also rises. This term appears in the expression for the optimal human capital threshold (6); whereas an increase in the growth rate of wages makes staying in school more desirable, a rise in the interest rate makes extended schooling less palatable. In the long run, the latter effect dominates, so by a combination of (6) and (14), $z^{*}$ eventually rises. In other words, we find that the long-run schooling-adjusted effective capital-to-labor ratio rises in response to an acceleration of technological progress, once proper adjustment is made for the optimal response of targeted human capital and the greater complementarity of schooling with physical capital than with raw labor. Finally, with an elasticity of substitution between capital and labor less than one, a rise in the schooling-adjusted effective capital-labor ratio spells a reallocation of income from capital to labor. To avoid possible confusion, note that although faster productivity growth reduces the steady state human capital target conditional on technology levels, equation (12) shows that an increase in the rate of capital-augmenting technological progress $\gamma_{K}$ also raises the rate at which $h_{t}^{*}$ increases as technology improves. Conversely, a productivity slowdown that raises the human capital target can also reduce the long-run growth of schooling.

Recent history has, however, witnessed not an acceleration in technological progress, but rather a slowdown in productivity growth; see, for example, Gordon (2010, 2016) and Fernald (2014). Our analysis suggests that a productivity slowdown will contribute to a redistribution of income from labor to capital in a world of capital-skill complementarity with ongoing gains in educational attainment. This could be a partial explanation for the recent fall in the global labor share. ${ }^{17}$ Indeed, in their study of the functional distribution of income in the United States, the United Kingdom and France from the late 1800's until recently, Charpe et al. (2019) find long cycles in the labor share that are positively correlated with growth in per capita income.

\section{Concluding Remarks}

We see three main contributions in this paper.

First, we have shown that education affects the division of national income between capital and labor in the presence of capital-skill complementarity. When skills and capital are complementary, the accumulation of embodied human capital raises the marginal return to physical capital and thus the share of income that accrues to any given stock of machinery and equipment. Moreover, optimal investment in education induces a negative correlation between the level of human capital and the return to physical capital in the presence of capital-skill complementarity. In such circumstances, using time-series correlation between capital returns and capital shares will produce upwardly biased estimates of the elasticity of substitution between capital and labor.

Second, features of the growth process will affect long run factor shares in the presence of capital-skill complementarity, even if those shares are stable in a steady state. We have shown that an increase in rates of technological progress will redistribute income from capital to labor and, conversely, a productivity slowdown will boost the capital share. The effects work through the endogenous response of investments in schooling. We have made these points in a neoclassical model of growth with competitive goods and factor markets and exogenous technological

\footnotetext{
${ }^{17}$ In the appendix, we discuss how to calibrate the model and explore its quantitative properties. We find that, for plausible calibrations, a productivity slowdown that reduces trend labor productivity growth by one percentage point increases capital's income share by several percentage points. The parameter restrictions imposed in Assumption 3 are satisfied in all our calibrations.
} 
progress. But similar mechanisms exist in models with imperfect competition and endogenous growth. Many models of automation and robotization feature capital-skill complementarity, as automated equipment and robots are operated by more-skilled workers while substituting closely for less-skilled workers. Therefore, the spread of robots in the production process is bound to affect the distribution of income across skill groups.

Third, we have developed a growth model that admits balanced growth and stable factor shares, despite ongoing capital-augmenting technical progress, ongoing growth in educational attainment, ongoing changes in labor force participation, and elasticities of substitution between factors that differ from one. Moreover, we have done so in a setting with overlapping generations, where the arrival of new cohorts introduces heterogeneity in schooling choices and labor force participation that makes aggregation potentially complex. The combination of perpetual youth à la Yaari (1965) and Blanchard (1985), human capital accumulation à la Ben Porath (1967) and capital-skill complementarity à la Grossman et. al (2017a) solves the aggregation problem. This purely technical contribution may prove useful in other contexts.

Our paper suggests several directions for future research. On the theoretical side, one might wish to move away from the assumption of "perpetual youth" to a more realistic model with finite lifetimes. However, such a modification would likely threaten existence of a BGP and would surely complicate dynamics, as is evident from Cass and Yaari (1967), who show that multiple steady states and complex transition dynamics can emerge even in a simple neoclassical setting that neglects human capital accumulation. On the empirical side, perhaps the most pressing need is for estimates of the degree of capital-skill complementarity in aggregate production. Not only is such complementarity necessary for our theoretical results, but the degree of complementarity determines the quantitative importance of the mechanism we highlight as well as the relationship between human capital accumulation and output that would underpin a growth-accounting exercise using our production function. We note that, given exogenous variation in the capital rental rate $R$ and human capital $h$, equation (1) could be used to simultaneously estimate capital-skill complementarity and the elasticity of substitution between capital and raw labor. 


\section{REFERENCES}

Acemoğlu, Daron, 2003. "Labor- and Capital-Augmenting Technical Change," Journal of the European Economic Association 1(1), 1-37.

Attanasio, Orazio and Weber, Guglielmo, 1993. "Consumption Growth, the Interest Rate and Aggregation," Review of Economic Studies 60(3), 631-49.

Ben Porath, Yoram, 1967. "The Production of Human Capital and the Life Cycle of Earnings," Journal of Political Economy 75(4, Pt. I), 352-65.

Blanchard, Olivier, 1985. "Debt, Deficits, and Finite Horizons," Journal of Political Economy 93(2), 223-47.

Blanchard, Olivier and Fischer, Stanley, 1989. Lectures on Macroeconomics, Cambridge: The MIT Press.

Campbell, John Y., 2003. "Consumption-Based Asset Pricing," ch. 13 in G.M. Constantanides, M. Harris and R.M. Stultz, eds., Handbook of the Economics of Finance, vol. 1B, Amsterdam: Elsevier.

Cass, David and Yaari, Menachem E., 1967. 'Individual Saving, Aggregate Capital Accumulation, and Efficient Growth," in K. Shell, ed., Essays in the Theroy of Optimal Economic Growth, Cambridge MA: MIT Press.

Charpe, Matthieu, Bridji, Slim, and McAdam, Peter, 2019. "Labor Share and Growth in the Long Run," Macroeconomic Dynamics, 1-38, doi:10.1017/S1365100518001025.

Chirinko, Robert S., 2008. " $\sigma$ : The Long and the Short of It," Journal of Macroeconomics 30(2), 671-86.

Elsby, Michael W. L., Hobijn, Bart, and Sahin, Aysegul, 2013. "The Decline of the U.S. Labor Share," Brookings Papers on Economic Activity 47(2), 1-63.

Fernald, John G., 2014. "Productivity and Potential Output Before, During, and After the Great Recession," Federal Reserve Bank of San Francisco Working Paper 2014-15.

Gordon, Robert J., 1990. The Measurement of Durable Goods Prices, Chicago, IL: University of Chicago Press.

Gordon, Robert J., 2010. "Revisiting U.S. Productivity Growth over the Past Century with a View of the Future," NBER Working Paper No. 15834.

Gordon, Robert J., 2016. The Rise and Fall of American Growth: The U.S. Standard of Living Since the Civil War, Princeton: Princeton University Press.

Greenwood, Jeremy, Hercovitz, Zvi and Krusell, Per, 1997. "Long-Run Implications of Investment-Specific Technological Change," American Economic Review 87(3), 342-62.

Griliches, Zvi, 1969. "Capital-Skill Complementarity," The Review of Economics and Statistics 51(4), 465-68.

Grossman, Gene M., Helpman, Elhanan, Oberfield, Ezra and Sampson, Thomas A., 2017a. "Balanced Growth despite Uzawa," American Economic Review 107(4), 1293-1312.

Grossman, Gene M., Helpman, Elhanan, Oberfield, Ezra and Sampson, Thomas A., 2017b. "The Productivity Slowdown and the Declining Labor Share: A Neoclassical Exploration," NBER Working Paper No. 23853.

Hall, Robert E., 1988. "Intertemporal Substitution in Consumption," Journal of Political Economy 96(2), 339-57.

Herrendorf, Berthold, Herrington, Christopher, and Ákos Valentinyi, 2015. "Sectoral Tech- 
nology and Structural Transformation," American Economic Journal: Macroeconomics 7(4), 104-33.

Kaldor, Nicholas, 1961. "Capital Accumulation and Economic Growth," in F.A. Lutz and D.C. Hague, eds., The Theory of Capital: Proceedings of a Conference of the International Economic Association, London: Macmillan.

Keynes, John Maynard, 1939. "Relative Movements of Real Wages and Output," Economic Journal 193(49), 34-51.

Karabarbounis, Loukas and Neiman, Brent, 2014. "The Global Decline of the Labor Share," Quarterly Journal of Economics 129(1), 61-103.

Krusell, Per, Ohanian, Lee E., José-Victor Rios-Rull, and Violante, Giovanni L., 2000. "Capital-Skill Complementarity and Inequality: A Macroeconomic Analysis," Econometrica 68(5), 1029-63.

Lucas, Robert E., Jr., 1988. "On the Mechanics of Economic Development," Journal of Monetary Economics 22(1), 3-47.

Oberfield, Ezra and Raval, Devesh, 2020. "Micro Data and Macro Technology," Econometrica, forthcoming.

Uzawa, Hirofumi, 1961. "Neutral Inventions and the Stability of Growth Equilibrium," Review of Economic Studies 28(2), 117-24.

Uzawa, Hirofumi, 1965. "Optimal Technical Change in an Aggregate Model of Economic Growth," International Economic Review 6(1), 18-31.

Vissing-Jørgensen, Annette, 2002. "Limited Asset Market Participation and the Elasticity of Intertemporal Substitution," Journal of Political Economy 110(4), 825-53.

Yaari, Menachem, 1965. "Uncertain Lifetime, Life Insurance, and the Theory of the Consumer," Review of Economic Studies 32(2), 137-50.

Yogo, Motohiro, 2004. "Estimating the Elasticity of Intertemporal Substitution When Instruments are Weak," Review of Economics and Statistics 86(3), 797-810. 


\title{
Online Appendix for "Endogenous Education And Long-Run Factor SHARES"
}

by

\begin{abstract}
Gene M. Grossman, Elhanan Helpman, Ezra Oberfield and Thomas Sampson
\end{abstract}
September 2020

\section{Proofs from Section I}

\section{Capital-skill complementarity}

Let $G(K, S, U)$ be a three-factor production function that is homogeneous of degree one in $(K, S, U)$, twice continuously differentiable and has strictly positive first and second derivatives in all its arguments. Let $\sigma_{K J} \equiv \frac{G_{K} G_{J}}{G G_{K J}}$ for $J=S, U$. We show that Assumption 1 implies $\sigma_{K U}>\sigma_{K S}$. For the nested constant elasticity of substitution production function used by Krusell et al. (2000), $\sigma_{K U}>\sigma_{K S}$ if and only if (equipment) capital is more substitutable with unskilled labor than with skilled labor.

Assumption 1 requires $\varphi>0$ where

$$
\varphi \equiv \frac{d \ln \left(F_{h} / F_{L}\right)}{d \ln K}=\frac{K F_{K h}}{F_{h}}-\frac{K F_{K L}}{F_{L}}
$$

Let $L=S+U$ and $h=S / L$. Then we can write $F(K, L, h)=G(K, h L,(1-h) L)$, which is equivalent to $F(K, S+U, S /(S+U))=G(K, S, U)$. Differentiating yields

$$
\begin{aligned}
\sigma_{K U}-\sigma_{K S} & =\frac{F_{K}}{F} \frac{F_{L}-h F_{h} / L}{F_{K L}-h F_{K h} / L}-\frac{F_{K}}{F} \frac{F_{L}+(1-h) F_{h} / L}{F_{K L}+(1-h) F_{K h} / L}, \\
& =\frac{F_{K} F_{L} F_{h}}{L F} \frac{1}{G_{K U} G_{K S}}\left(\frac{F_{K h}}{F_{h}}-\frac{F_{K L}}{F_{L}}\right),
\end{aligned}
$$

which is positive if and only if $\varphi>0$.

\section{Derivation of equation (1)}

Let $k=K / L$. Output is homogeneous of degree one in $K$ and $L$ by Assumption 1, meaning that the optimal capital use equation can be written as $R=F_{K}(k, 1, h)$. Differentiating yields

$$
d k=\frac{F_{K}}{F_{K K}} d \ln R-\frac{F_{K h}}{F_{K K}} d h .
$$

Likewise, the capital share is given by $\theta=R k / F(k, 1, h)$ and differentiating implies

$$
d \theta=\theta d \ln R-\theta \frac{F_{h}}{F} d h+\frac{\theta(1-\theta)}{k} d k .
$$


Using (A.2) to substitute for $d k$ then gives

$$
d \theta=\theta\left[1+(1-\theta) \frac{F_{K}}{k F_{K K}}\right] d \ln R-\theta\left[\frac{F_{h}}{F}+(1-\theta) \frac{F_{K h}}{k F_{K K}}\right] d h .
$$

Noting that the homogeneity of $F$ implies $k F_{K K}=-F_{K L}$ and using equation (A.1) for $\varphi$, we can rearrange this expression to obtain equation (1).

\section{Proofs from Section II}

Optimal education: derivation of equation (6)

Let $\hat{F}(k, h)=F(k, 1, h)$ denote the production function in intensive form where $k=K / L$. Let $\kappa_{t}(h)$ be the units of physical capital that are combined with a unit of labor bearing human capital $h$ at time $t$. Optimal capital use requires

$$
\hat{F}_{k}\left(\kappa_{t}(h), h\right)=R,
$$

and since competitive producers make zero profits, the wage schedule is given by

$$
w_{t}(h)=\hat{F}\left(\kappa_{t}(h), h\right)-R \kappa_{t}(h) .
$$

Differentiating these expressions and suppressing the arguments of $\hat{F}\left(\kappa_{t}(h), h\right)$ yields

$$
\begin{array}{rlrl}
\kappa_{t}^{\prime}(h) & =-\frac{\hat{F}_{k h}}{\hat{F}_{k k}}, & \frac{\partial \kappa_{t}(h)}{\partial t} & =g_{R} \frac{\hat{F}_{k}}{\hat{F}_{k k}}, \\
w_{t}^{\prime}(h)=\hat{F}_{h}, & \frac{\partial w_{t}(h)}{\partial t} & =\frac{\partial \hat{F}}{\partial t}-g_{R} \kappa_{t}(h) \hat{F}_{k},
\end{array}
$$

where $g_{R}$ denotes the growth rate of $R$. Note also that using the intensive form production function we can write: $\theta=\kappa_{t}(h) \hat{F}_{k} / \hat{F} ; \sigma=-\hat{F}_{k}(1-\theta) /\left(\kappa_{t}(h) \hat{F}_{k k}\right) ; \varphi=\kappa_{t}(h) \hat{F}_{k h} / \hat{F}_{h}-\theta / \sigma$.

Each individual chooses her labor supply path to maximize the expected present value of lifetime earnings. Consider an individual with human capital $h_{t}$ at time $t$ and labor supply path $\ell_{\tau}$ for $\tau \geq t$. Let $\tilde{\ell}_{\tau}$ be an alternative labor supply path defined by

$$
\tilde{\ell}_{\tau}= \begin{cases}\ell_{\tau}+\epsilon, & \tau \in[t, t+\Delta], \\ \ell_{\tau}-\epsilon, & \tau \in(t+\Delta, t+2 \Delta], \\ \ell_{\tau}, & \tau>t+2 \Delta .\end{cases}
$$

where $\epsilon \in \mathbb{R}$ and $\Delta>0$. The individual's human capital under labor supply path $\tilde{\ell}_{\tau}$ is given by

$$
\tilde{h}_{\tau}= \begin{cases}h_{\tau}-\epsilon(\tau-t), & \tau \in[t, t+\Delta], \\ h_{\tau}-\epsilon(t+2 \Delta-\tau), & \tau \in[t+\Delta, t+2 \Delta], \\ h_{\tau}, & \tau \geq t+2 \Delta .\end{cases}
$$


Note that this labor supply perturbation does not affect the individual's human capital outside the interval $(t, t+2 \Delta)$.

Let $S$ be the difference between the individual's expected present value of earnings under $\tilde{\ell}_{\tau}$ and under $\ell_{\tau}$. We have

$$
\begin{aligned}
S & =\int_{t}^{t+2 \Delta} e^{-\int_{t}^{\tau}\left(r_{s}+\nu\right) d s}\left[\tilde{\ell}_{\tau} w_{\tau}\left(\tilde{h}_{\tau}\right)-\ell_{\tau} w_{\tau}\left(h_{\tau}\right)\right] d \tau \\
& =\int_{t}^{t+\Delta} e^{-\int_{t}^{\tau}\left(r_{s}+\nu\right) d s}\left\{\ell_{\tau}\left(w_{\tau}\left[h_{\tau}-\epsilon(\tau-t)\right]-w_{\tau}\left[h_{\tau}\right]\right)+\epsilon w_{\tau}\left[h_{\tau}-\epsilon(\tau-t)\right]\right\} d \tau \\
& +\int_{t+\Delta}^{t+2 \Delta} e^{-\int_{t}^{\tau}\left(r_{s}+\nu\right) d s}\left\{\ell_{\tau}\left(w_{\tau}\left[h_{\tau}-\epsilon(t+2 \Delta-\tau)\right]-w_{\tau}\left[h_{\tau}\right]\right)-\epsilon w_{\tau}\left[h_{\tau}-\epsilon(t+2 \Delta-\tau)\right]\right\} d \tau,
\end{aligned}
$$

where the second equality uses the expressions for $\tilde{\ell}_{\tau}$ and $\tilde{h}_{\tau}$ above. Expressing the functions in the integrands as Taylor series around $t$, computing the integrals and dropping terms that are $o\left(\Delta^{2}\right)$ implies that for $\Delta$ close to zero

$$
S \approx \epsilon \Delta^{2}\left[\left(r_{t}+\nu\right) w_{t}\left(h_{t}\right)-w_{t}^{\prime}\left(h_{t}\right)-\frac{\partial w_{t}\left(h_{t}\right)}{\partial t}\right]
$$

The intuition for this expression is as follows. When $\epsilon>0$, switching from labor supply path $\ell_{\tau}$ to $\tilde{\ell}_{\tau}$ means working more today and less tomorrow. The benefit of this switch is $\left(r_{t}+\nu\right) w_{t}\left(h_{t}\right)$, which equals the increase in the expected present value of earnings from bringing forward the time at which labor income is received. The costs of delaying schooling are: $w_{t}^{\prime}\left(h_{t}\right)$, which gives the decline in earnings from having lower human capital tomorrow, and; $\frac{\partial w_{t}\left(h_{t}\right)}{\partial t}$, which is positive when wages are increasing over time. Since human capital accumulation and labor supply are both linear in $\ell_{t}$, agents for whom the benefits of delaying schooling exceed the costs will choose to work full-time, while agents for whom the costs are greater will devote all their time to schooling.

Agents are indifferent between working and learning if and only if the right hand side of (A.6) equals zero for all $\epsilon$, which requires

$$
\tilde{S}_{t}\left(h_{t}\right) \equiv\left(r_{t}+\nu\right) w_{t}\left(h_{t}\right)-w_{t}^{\prime}\left(h_{t}\right)-\frac{\partial w_{t}\left(h_{t}\right)}{\partial t}=0 .
$$

We now make the following assumption

ASSUMPTION A.1: The production function and parameters of the economy are such that for all $t$

(i) There exists $h_{t}^{*}>0$ such that $\tilde{S}_{t}\left(h_{t}^{*}\right)=0$;

(ii) $\Gamma_{t}\left(h_{t}^{*}\right)>0$ for all $k$ where

$$
\Gamma_{t} \equiv \frac{1}{\hat{F}}\left[\left(\hat{F}_{h}+\frac{\partial \hat{F}}{\partial t}-g_{R} \kappa_{t}\left(h_{t}^{*}\right) \hat{F}_{k}\right) \frac{\hat{F}_{h}}{\hat{F}-\kappa_{t}\left(h_{t}^{*}\right) \hat{F}_{k}}-\hat{F}_{h h}+\frac{\hat{F}_{k h}^{2}}{\hat{F}_{k k}}-\frac{\partial \hat{F}_{h}}{\partial t}-g_{R} \frac{\hat{F}_{k} \hat{F}_{k h}}{\hat{F}_{k k}}\right] .
$$

Assumption A.1.i imposes that a solution to equation (A.7) exists. This is a relatively weak 
restriction. To see why, note that $\tilde{S}_{t}\left(h_{t}\right)$ is continuous in $h_{t}$ whenever the production function is continuously differentiable in $k, h$ and $t$. Then if a solution does not exist, either all individuals work full-time with $\ell_{t}=1$ or all individuals are in full-time education with $\ell_{t}=0$. It is straightforward to impose sufficient conditions to rule out such equilibria. For example, if individuals with no human capital produce no output then $w_{t}(0)=0$, meaning that working full-time cannot be optimal for newborn agents. In addition, if the economy has a positive capital stock and the marginal product of capital is unbounded as the capital input approaches zero, then it cannot be optimal for all agents to be in full-time education.

Assumption A.1.ii is a second order condition for educational choice that ensures the solution to equation (A.7) is unique. To show this we differentiate $\tilde{S}_{t}\left(h_{t}\right)$ given by (A.7). Using equations (A.3)-(A.5) and setting $h_{t}=h_{t}^{*}$ yields $\tilde{S}_{t}^{\prime}\left(h_{t}^{*}\right)=\hat{F} \Gamma_{t}\left(h_{t}^{*}\right)$. Thus, the gradient of $\tilde{S}_{t}\left(h_{t}\right)$ is positive if $\tilde{S}_{t}\left(h_{t}\right)=0$.

This single-crossing property guarantees that equation (A.7) has a unique solution $h_{t}=h_{t}^{*}$. It also implies that $\tilde{S}_{t}\left(h_{t}\right)<0$ for all $h_{t}<h_{t}^{*}$ and $\tilde{S}_{t}\left(h_{t}\right)>0$ for all $h_{t}>h_{t}^{*}$. Consequently, individuals with human capital below the threshold $h_{t}^{*}$ prefer to study today and work tomorrow, while the opposite is true for individuals with human capital above $h_{t}^{*}$. Since labor supply is bounded on the interval $[0,1]$ it follows that optimal labor supply is given by $\ell_{t}=0$ if $h_{t}<h_{t}^{*}$ and $\ell_{t}=1$ if $h_{t}>h_{t}^{*}$.

Setting $h_{t}=h_{t}^{*}$ and rearranging equation (A.7) gives equation (6) in the paper. Taking the total derivative of this expression for given $t$ and using equations (A.3)-(A.5) together with the definitions of $\varphi, \sigma$ and $\theta$ yields

$$
d h_{t}^{*}=-\frac{1}{\Gamma_{t}} \frac{\sigma \varphi}{1-\theta} \frac{F_{h}}{F} d \ln R+\frac{1-\theta}{\Gamma_{t}}\left(d g_{w \mid h_{t}^{*}, t}-d r_{t}-d \nu\right)
$$

where $d g_{w \mid h_{t}^{*}, t}$ denotes the change in the growth rate of wages evaluated at $h_{t}^{*}$. Equation (A.8) shows that whenever there is capital-skill complementarity as defined in Assumption 1 (meaning $\varphi>0$ ) and the technical conditions in Assumption A.1 hold, an increase in the rental rate of capital $R$ reduces the optimal human capital threshold $h_{t}^{*}$. Moreover, even in the absence of capital-skill complementarity, the human capital threshold is increasing in the growth rate of wages, but decreasing in the real interest rate and the risk of death.

\section{Optimal human capital in a model of occupational choice}

Suppose there are two types of labor - skilled and unskilled - and $h$ denotes the fraction of the labor force that is skilled. Formally, let $S$ denote the skilled labor force and $U$ the unskilled labor force. Then $L=S+U$ and human capital $h=S / L$. Let $w^{U}$ denote the unskilled wage and $w^{S}=\psi w^{U}$ the skilled wage, where $\psi$ denotes the skill premium. For this economy the wage schedule $w_{t}(h)$ satisfies

$$
w_{t}(h)=\frac{w^{U} U+w^{S} S}{L}=w^{U}[1+h(\psi-1)],
$$

implying that $w_{t}^{\prime}(h)=w^{U}(\psi-1)$.

Competitive firms hire capital and labor taking the rental rate and the wage schedule as given, implying that equations (A.3)-(A.5) hold. Using the wage schedule in (A.9) to differentiate (A.3), (A.4) together with the expression for $w_{t}^{\prime}(h)$ in (A.5) we obtain 


$$
d h=-\frac{1}{\tilde{\Gamma}_{t}} \frac{\sigma \varphi}{1-\theta} d \ln R-\frac{1}{\tilde{\Gamma}_{t}} \frac{1}{1+h(\psi-1)} \frac{d \psi}{\psi-1},
$$

where

$$
\tilde{\Gamma}_{t} \equiv \frac{1}{\hat{F}_{h}}\left(\frac{\hat{F}_{k h}^{2}}{\hat{F}_{k k}}-\hat{F}_{h h}\right),
$$

and we assume $\tilde{\Gamma}_{t}>0$ for all $t$ to ensure that the second order condition for profit maximization holds. Thus, the relative demand for skilled labor is declining in the skill premium $\psi$ and also decreasing in the capital rental rate $R$ whenever there is capital-skill complementarity.

Equation (A.10) gives demand for human capital conditional on the skill premium. However, when individuals choose whether or not to invest in becoming skilled, the skill premium also affects occupational choice. Suppose all newborns are unskilled, but have the opportunity to become skilled workers by attending school for $\zeta$ periods. Apart from this change to the education technology, the economy is as specified in Section II.

To maximize dynastic utility, each individual chooses the occupation that offers the highest expected present value of lifetime earnings. We restrict attention to equilibria where at each instant some, but not all, unskilled individuals choose to become skilled. This requires that unskilled individuals are indifferent over whether or not to attend school. Skilled agents earn nothing for $\zeta$ periods and then receive the skilled wage, while unskilled agents always earn the unskilled wage. Therefore, the indifference condition at time $\tau$ is

$$
\int_{\tau}^{\infty} e^{-\int_{\tau}^{t}\left(r_{z}+\nu\right) d z} w_{t}^{U} d t=\int_{\tau+\zeta}^{\infty} e^{-\int_{\tau}^{t}\left(r_{z}+\nu\right) d z} \psi_{t} w_{t}^{U} d t
$$

where the left hand side is the expected present value of earnings of an unskilled worker and the right hand side is the expected present value of earnings of an individual that chooses to become skilled. Differentiating the indifference condition with respect to $\tau$ yields

$$
w_{\tau}^{U}=e^{-\int_{\tau}^{\tau+\zeta}\left(r_{z}+\nu\right) d z} \psi_{\tau+\zeta} w_{\tau+\zeta}^{U}
$$

Thus, the unskilled wage at time $\tau$ equals the expected present value of the skilled wage at time $\tau+\zeta$, which is when skilled agents who start schooling at $\tau$ join the labor force.

Let $g_{w}^{U}(t, \zeta)=w_{t}^{U} / w_{t-\zeta}^{U}$ denote growth in the unskilled wage between $t-\zeta$ and $t$ and $r(t, \zeta)=$ $e^{\int_{t-\zeta}^{t}\left(r_{z}+\nu\right) d z}$ be the inverse of the discount factor used to value time $t$ earnings at time $t-\zeta$. Then differentiating (A.11) with $\tau=t-\zeta$ gives

$$
\frac{d \psi_{t}}{\psi_{t}}=\frac{d r(t, \zeta)}{r(t, \zeta)}-\frac{d g_{W}^{U}(t, \zeta)}{g_{W}^{U}(t, \zeta)},
$$

and using this expression to substitute for $d \psi_{t}$ in (A.10) yields

$$
d h_{t}=-\frac{1}{\tilde{\Gamma}_{t}} \frac{\sigma \varphi}{1-\theta} d \ln R+\frac{1}{\tilde{\Gamma}_{t}} \frac{1}{1+h_{t}\left(\psi_{t}-1\right)} \frac{\psi_{t}}{\psi_{t}-1}\left[\frac{d g_{w}^{U}(t, \zeta)}{g_{w}^{U}(t, \zeta)}-\frac{d r(t, \zeta)}{r(t, \zeta)}\right]
$$


Equation (A.12) is analogous to equation (A.8) from the baseline model. As in the baseline model, an increase in the capital rental rate reduces equilibrium human capital $h$ whenever there is capital-skill complementarity. In addition, $h$ is increasing in the growth rate of unskilled wages, but decreasing in the compound interest rate during the period when individuals attend school. This shows that the qualitative results concerning the determinants of optimal human capital derived in Section II continue to hold in a model of occupational choice with endogenous supplies of skilled and unskilled labor.

\section{Proofs from Section III}

\section{Proof of Lemma 1 and Proposition 1}

Imposing the functional form in Assumption 2 and noting that optimal capital use satisfies equation (8), a firm that hires labor with human capital $h_{t}$ at time $t$ has capital share $\theta\left[z_{t}\left(h_{t}\right)\right]$ where $\theta(z) \equiv z f^{\prime}(z) / f(z)$ and $z_{t}(h) \equiv e^{-(a+b) h \frac{A_{t} \kappa_{t}(h)}{B_{t}}}$. Moreover, equation (8) implies $z_{t}$ is strictly decreasing in $h_{t}$ and Grossman et al. (2017a) show that $\theta(z)$ is strictly decreasing in $z$. It follows that $\theta\left[z_{t}\left(h_{t}\right)\right]$ is strictly increasing in $h_{t}$.

Differentiating the wage schedule in (9) yields

$$
\frac{1}{w_{t}(h)} \frac{\partial w_{t}(h)}{\partial t}=\gamma_{L}+\left(g_{A}-g_{R}\right) \frac{\theta\left[z_{t}(h)\right]}{1-\theta\left[z_{t}(h)\right]},
$$

and substituting this expression together with equation (14) into equation (A.7) gives

$$
\tilde{S}_{t}\left(h_{t}\right)=\left(r_{t}+\nu-b-\gamma_{L}+\left(a+g_{R}-g_{A}\right) \frac{\theta\left[z_{t}\left(h_{t}\right)\right]}{1-\theta\left[z_{t}\left(h_{t}\right)\right]}\right) w_{t}\left(h_{t}\right) .
$$

Now, assume that for all $t$ there exists $h_{t}^{*}>0$ that solves $\tilde{S}_{t}\left(h_{t}^{*}\right)=0$ and that $a+g_{R}-g_{A}>0$, which ensures $\tilde{S}_{t}^{\prime}\left(h_{t}^{*}\right)>0$ because $\theta\left[z_{t}\left(h_{t}\right)\right]$ is strictly increasing in $h_{t}$. We prove below that these assumptions hold on a balanced growth path (BGP). Then Assumption A.1 is satisfied. It follows that $h_{t}^{*}$ defines a human capital threshold such that at time $t$ all individuals with human capital below $h_{t}^{*}$ are in full-time education and all individuals with human capital above $h_{t}^{*}$ work full-time.

Next, suppose the economy is on a BGP. The no arbitrage condition for capital accumulation implies that on a BGP where the interest rate is constant $g_{R}=-g_{q}$. Therefore, on a BGP $a+g_{R}-g_{A}=a-\gamma_{K}$, which is strictly positive by Assumption 3.i. It follows that $a+g_{R}-g_{A}>0$ on a BGP as assumed above.

Setting $\tilde{S}_{t}\left(h_{t}^{*}\right)=0$ implies the human capital threshold on a BGP satisfies

$$
\frac{\theta\left[z_{t}\left(h_{t}^{*}\right)\right]}{1-\theta\left[z_{t}\left(h_{t}^{*}\right)\right]}=\frac{b+\gamma_{L}-(r+\nu)}{a-\gamma_{K}}
$$

showing that $z_{t}\left(h_{t}^{*}\right)=z^{*}$ must be constant on a BGP which proves equation (11) in Lemma 1. Differentiating (8) with respect to time while holding $z_{t}\left(h_{t}^{*}\right)$ constant then yields

$$
\dot{h}_{t}^{*}=\frac{\gamma_{K}}{a} .
$$

Therefore, in order to keep their human capital rising at the same rate as $h_{t}^{*}$, individuals that are in the labor force must choose labor supply $\ell=1-\gamma_{K} / a$ as claimed in equation (10) of 
Lemma 1.

At time $t$ any individuals with human capital above $h_{t}^{*}$ work full-time. Consequently, on a BGP it is not possible for individuals to have human capital above $h_{t}^{*}$ since $h_{t}^{*}$ is growing over time. Given this observation, the remaining properties of the unique BGP can be derived as in the discussion following Lemma 1 in the paper. In particular, equation (16) gives the real interest rate on the BGP and substituting (16) into (A.13) gives (18), which determines the BGP value of $\theta$. Assumption 3.iii ensures the discount rate is sufficiently large that dynastic utility is finite on the BGP. Finally, since $g_{R}=-g_{q}$ and the real interest rate $r$ satisfies (16), Assumption 3.ii guarantees that, as assumed above, for all $t$ there exists $h_{t}^{*}>0$ that solves $\tilde{S}_{t}\left(h_{t}^{*}\right)=0$.

This completes the proof that there exists a unique BGP. In our working paper Grossman et al. (2017b) we analyze the stability of the BGP and show that the BGP is locally saddle-path stable in a calibrated version of the model.

\section{Proof of Proposition 2}

Differentiating equation (18) with respect to $\gamma_{K}$ yields

$$
\frac{1}{(1-\theta)^{2}} \frac{\partial \theta}{\partial \gamma_{K}}=-\frac{\eta-1}{a-\gamma_{K}} \frac{b-\lambda}{a}-\frac{(\eta-1)\left(\gamma_{L}+\frac{b-\lambda}{a} \gamma_{K}\right)-\lambda+\nu+\rho}{\left(a-\gamma_{K}\right)^{2}} .
$$

The first term on the right hand side is negative when $\eta>1$ since Assumption 2 imposes $b>\lambda$. The second term on the right hand side is negative by Assumption 3.iii which guarantees finite utility on the BGP. It follows that an increase in $\gamma_{K}$ reduces $\theta$ or, equivalently, that a reduction in $\gamma_{K}$ reduces labor's share of income.

Differentiating equation (18) with respect to $\gamma_{L}$ yields

$$
\frac{1}{(1-\theta)^{2}} \frac{\partial \theta}{\partial \gamma_{L}}=-\frac{\eta-1}{a-\gamma_{K}}
$$

which is negative if and only if $\eta>1$. Thus, a reduction in $\gamma_{L}$ increases $\theta$ and lowers labor's share of income.

\section{Quantitative Exploration}

We present the results of calibrating the model and quantifying the impact on factor shares of a one percentage point reduction in trend growth of labor productivity. For a complete description of the calibration and quantitative analysis see our working paper Grossman et al. (2017b).

We rely on the empirical literature to set some of our parameters and choose others to match moments from the U.S. historical experience as detailed in Table A1. Conveniently, steady state factor shares can be calculated without assuming a functional form for $\tilde{F}(\cdot)$. However, we have no firm basis for specifying the magnitude of the capital-skill complementarity that is reflected in the parameter $a$ in $\tilde{F}\left(e^{-a h} A_{t} K, e^{b h} B_{t} L\right)$. Given our other moments, this parameter would be pinned down if we knew the bias of technical progress in the pre-slowdown period. However, the Diamond-McFadden "Impossibility Theorem" tells us that we cannot identify this from time series data. Consequently, we pursue two different approaches to calibrating $a$. First, we introduce plausible but ad hoc assumptions about the bias in technical progress along the initial BGP. Then, we employ cross-sectional data for U.S. regions and industries in a crude attempt to estimate $a$ directly. 
Table A1 - TArgeted Moments And Parameters

\begin{tabular}{lcc}
\hline \hline Parameter/Moment & & Value \\
\hline Birth rate & $\lambda$ & $2.16 \%$ \\
Death rate & $\nu$ & $0.95 \%$ \\
Internal Rate of Return on schooling & $\iota$ & $10 \%$ \\
Capital share & $\theta$ & 0.35 \\
Growth in labor productivity & $\gamma_{L}+\frac{b}{a} \gamma_{K}$ & 0.024 \\
Increase in schooling & $\dot{s}_{\tau}=\frac{\gamma_{K}}{a-\gamma_{K}}$ & 0.088 \\
Intertemporal elasticity of substitution & $\frac{1}{\eta}$ & 0.5 \\
\hline
\end{tabular}

Table A2-Response of Capital Share to Productivity Slowdown: Ad Hoc Examples

\begin{tabular}{|c|c|c|c|c|c|c|}
\hline \multicolumn{7}{|c|}{$\gamma_{K}=\gamma_{L}=1.1 \% \Rightarrow a=0.132, b=0.164$} \\
\hline & $\gamma_{K}$ & $\gamma_{L}$ & $\begin{array}{l}\text { Growth in } \\
\text { per capita } \\
\text { Income }\end{array}$ & $\begin{array}{c}\text { Annual } \\
\text { Increase in } \\
\text { Schooling }\end{array}$ & $\begin{array}{c}\text { Interest } \\
\text { Rate }\end{array}$ & $\begin{array}{l}\text { Capital } \\
\text { Share }\end{array}$ \\
\hline Baseline & $1.1 \%$ & $1.1 \%$ & $2.2 \%$ & 0.09 & $10.0 \%$ & 0.35 \\
\hline$\gamma_{L} \downarrow$ & $1.1 \%$ & $0.1 \%$ & $1.2 \%$ & 0.09 & $8.0 \%$ & 0.383 \\
\hline$\gamma_{K} \downarrow$ & $0.3 \%$ & $1.1 \%$ & $1.4 \%$ & 0.02 & $8.3 \%$ & 0.39 \\
\hline \multicolumn{7}{|c|}{$\overline{g_{q}=2.0 \%, g_{A}=\gamma_{L}=0.4 \% \Rightarrow a=0.293, b=0.251}$} \\
\hline & $\gamma_{K}$ & $\gamma_{L}$ & $\begin{array}{l}\text { Growth in } \\
\text { per capita } \\
\text { Income }\end{array}$ & $\begin{array}{c}\text { Annual } \\
\text { Increase in } \\
\text { Schooling }\end{array}$ & $\begin{array}{c}\text { Interest } \\
\text { Rate }\end{array}$ & $\begin{array}{c}\text { Capital } \\
\text { Share }\end{array}$ \\
\hline Baseline & $2.4 \%$ & $0.4 \%$ & $2.2 \%$ & 0.09 & $10.0 \%$ & 0.35 \\
\hline$\gamma_{L} \downarrow$ & $2.4 \%$ & $-0.6 \%$ & $1.2 \%$ & 0.09 & $8.0 \%$ & 0.365 \\
\hline$\gamma_{K} \downarrow$ & $1.2 \%$ & $0.4 \%$ & $1.3 \%$ & 0.04 & $8.2 \%$ & 0.368 \\
\hline
\end{tabular}

Table A2 shows the quantitative results when we make ad-hoc assumptions about the bias of technical progress. For the top panel, we assume that technical change in the pre-slowdown period was factor neutral, so that $\gamma_{K}=\gamma_{L}$. For the lower panel, we assume that the observed average decline in investment goods prices of $2 \%$ per year represents the full extent of investment-specific technical change, and that the disembodied technological progress was factor neutral $\left(g_{A}=\gamma_{L}\right)$. In both cases we report the new steady state following a permanent one percentage point slowdown in labor productivity growth caused by a decline in either labor-augmenting or capital-augmenting technical progress. We see that the increase in capital's share of national income following a productivity slowdown varies between 1.5 and 4 percentage points.

Our second approach to calibrating the model estimates $a$ from the association between labor shares and wage growth across states and industries in the US, details are given in Grossman et al. (2017b). We find an inverse relationship between the average labor share in the stateindustry and the average rate of wage growth, as would be predicted by our model assuming that the US has an integrated national capital market. Our preferred estimate implies $a=0.19$.

In Table A3, we repeat the exercise of simulating the effects of a one percentage point slowdown in annual labor-productivity growth. In this case, the values of $\gamma_{K}$ and $\gamma_{L}$ in the baseline 
Table A3-Response of Capital Share to Productivity Slowdown: Estimates of Capital-Schooling Complementarity using Cross-Sectional Data

\begin{tabular}{lcccccc}
\hline \hline \multicolumn{7}{c}{ Central Estimate of $a: a=0.19, b=0.195$} \\
\hline
\end{tabular}

calibration are those needed for the model to match the annual increase in schooling, the capital share, the rate of return on education, and the growth rate of labor productivity in the pre-slowdown period. Again, we simulate the slowdown in labor-productivity growth as being the result of either a deceleration of capital-augmenting technological progress or of laboraugmenting technological progress.

We find that a one percentage point slowdown in trend productivity growth can account for a sizeable shift in income from labor to capital. With the parameters reflected in the table, the capital share rises between two and three percentage points. In our working paper we also analyze the sensitivity of the quantitative results and argue that once we admit a reasonable amount of capital-skill complementarity (as captured by the parameter $a$ ), a productivity slowdown can account for a substantial redistribution of income from labor to capital for all plausible values of the other parameters. 